Supporting Information for

\title{
Single Molecule Force Spectroscopy Reveals Distinctions in Key \\ Biophysical Parameters of $\alpha \beta$ T-Cell Receptors Compared with Chimeric Antigen Receptors Directed at the Same Ligand
}

Authors: Debasis Banik ${ }^{1}$, Maryam Hamidinia ${ }^{2,3,4}$, Joanna Brzostek ${ }^{2,3,4}$, Ling $\mathrm{Wu}^{2,3,4}$, Hannah M. Stephens ${ }^{1}$, Paul A. MacAry ${ }^{2,3,4}$, Ellis L. Reinherz ${ }^{5,6}$, Nicholas R. J. Gascoigne ${ }^{2,3,4 *}$ and Matthew J. Lang $1,7^{*}$

${ }^{1}$ Department of Chemical and Biomolecular Engineering, Vanderbilt University, Nashville, TN 37235, USA.

${ }^{2}$ Translational Immunology Research Program, Yong Loo Lin School of Medicine, National University of Singapore, Singapore 117545, Singapore.

${ }^{3}$ Translational Cancer Research Program, Yong Loo Lin School of Medicine, National University of Singapore, Singapore 117545, Singapore.

${ }^{4}$ Department of Microbiology and Immunology, Yong Loo Lin School of Medicine, National University of Singapore, Singapore 117545, Singapore.

${ }^{5}$ Laboratory of Immunobiology, Dana-Farber Cancer Institute, Boston, MA 02115, USA.

${ }^{6}$ Department of Medical Oncology, Dana-Farber Cancer Institute and Department of Medicine, Harvard Medical School, Boston, MA 02115, USA.

${ }^{7}$ Department of Molecular Physiology and Biophysics, Vanderbilt University School of Medicine, Nashville, TN 37235, USA.

${ }^{*}$ Corresponding authors, e-mail: micnrjg@nus.edu.sg ; matt.lang@vanderbilt.edu 


\section{Content:}

1. Materials and Methods

1.1. Assay details of SMSC (p. S3-S4)

1.2. Assay details of SM (p. S4-S5)

1.3. Generation of $\alpha \beta$ TCR and CAR T-cells (p. S5)

2. Flow cytometry results of $\alpha \beta$ TCR (p. S6)

3. Flow cytometry results of LMP2 CAR, LMP1 CAR and CD19 CAR (p. S7-S9)

4. SMSC traces of LMP1 CAR T-cells (p. S10)

5. SMSC traces of CD19 CAR T-cells (p. S11)

6. Conformational transition analysis of $\alpha \beta$ TCR and CAR (p. S12)

7. Conformational transition frequency vs. force and cumulative frequency vs. transition time plot for $\alpha \beta$ TCR and CAR systems (p. 13)

8. Tables detailing the number of SMSC and SM traces and conformational transitions at different force ranges (p. 14) 


\section{Materials and Methods}

Single Molecule measurement on isolated Single Cells (SMSC) Assay. Tethers for SMSC (depicted in Fig. 1A) assays were constructed using antidigoxygenin-coated polystyrene beads (1.0 $\mu \mathrm{m}$ in diameter, Spherotech Inc.) to tether the digoxigenin-labeled, 3,500-bp DNA at one end. At the other end, a sulfo-SMCC (Pierce) reaction was used to bind the free thiol group of the half anti-biotin antibody. This half anti-biotin antibody was prepared by reducing antibiotin using 2-Mercaptoethylamine $\cdot \mathrm{HCl}$ (2-MEA). Finally, biotin-labeled pMHC/CD19 was linked to the half anti-biotin antibody. Specifically, $0.5 \mu \mathrm{L} 0.25 \%(\mathrm{w} / \mathrm{v})$ anti-digoxygenin beads were washed two times by PBS buffer containing $0.02 \%$ Tween 20 (PBST) and were incubated with $5 \mu \mathrm{L}$ of half-anti-biotin functionalized DNA $(\sim 25 \mathrm{ng} / \mu \mathrm{L})$. The bead surface was saturated with these 3,500-bp DNA tethers to reduce nonspecific binding between the bead and cell surface. After $1 \mathrm{~h}$ of incubation, the DNA-labeled bead was washed three times with PBST buffer and then resuspended in a solution containing $5 \mu \mathrm{L}$ of $200 \mathrm{pM}$ biotinylated pMHC/CD19 in PBS buffer for $1 \mathrm{~h}$ incubation. After two washes with PBST buffer, the bead slurry was diluted 150-fold for bond lifetime measurements. All of the incubations were performed at room temperature.

$\alpha \beta$ TCR Jurkat, CAR Jurkat and CD19 CAR Jurkat T-cells were cultured in selection medium [500 mL RPMI medium 1640 (Life Technology) plus 50 mL FBS plus 5 mL PenicillinStreptomycin (Life Technology) and $5 \mathrm{~mL}$ L-glutamine (Life Technology)] and reached the $\log$ phase before the experiments. (Here, all TCR designations refer to $\alpha \beta$ TCRs unless indicated otherwise.) Cells were washed one time with PBS and then kept in colorless complete RMPI 1640 (Life Technology) plus FBS medium at 2 million/mL; $20 \mu \mathrm{L}$ of cells were introduced into the flow chamber, and cells were bound to a $\mathrm{KOH}$ etched coverslip prepared as described previously (1). The coverslip surface was further blocked by $1 \mathrm{mg} / \mathrm{mL}$ casein (Sigma-Aldrich) in PBS buffer (1). After a 10 -min incubation at $37^{\circ} \mathrm{C}$, the pMHC/CD19-DNA 
bead slurry $(20 \mu \mathrm{L})$ was introduced into the flow cell. The tether-functionalized bead was trapped and brought in the vicinity of T-cells to form a stable tether. Tether formation was verified and then loaded by displacing the cell relative to the fixed trap using fine motions of the piezo stage. Bead positions were sampled at $3 \mathrm{kHz}$, antialias-filtered at $1.5 \mathrm{kHz}$, and recorded until complete rupture. Assay was performed at $37^{\circ} \mathrm{C}$.

Single-Molecule (SM) Assay. For single-molecule measurements (depicted in Fig. 1B), a complex of LMP2 CAR antibody/BB7.2 and pMHC was tethered between a single trapped bead and glass surface. The overall assay geometry included a biotinylated pMHC linked to the half anti-biotin-3,500-bp DNA-antidigoxygenin-coated beads (as described in SMSC). The DNA served as a spacer between the bead and pMHC. The LMP2 CAR antibody/BB7.2 was immobilized on a PEG functionalized coverglass surface.

The DNA linker was constructed by PCR of a 3,500-bp region of the M13mp18 plasmid with $5^{\prime}$ primers of an amino group and digoxigenin. The 5' amino group was cross-linked to the free thiol group of the half anti-biotin antibody using sulfo-SMCC (Pierce) reaction. A $10-\mu \mathrm{L}$ flow cell was prepared using two pieces of double-sided sticky tape. Cover-glass surfaces were coated with functionalized PEG silane $99 \%$ mixed with $1 \%$ biotin-PEG silane similar to previously described work (2). Streptavidin $(50 \mu \mathrm{g} / \mathrm{mL})$ was introduced into the flow cell, incubated for $10 \mathrm{~min}$, and washed with PBS buffer. Previously mixed $5 \mu \mathrm{L}$ of biotinylated Protein $\mathrm{G}(1 \mathrm{mg} / \mathrm{mL}), 5 \mu \mathrm{L}$ of LMP2 CAR antibody/BB7.2 $(50 \mathrm{ng} / \mu \mathrm{L} / 100 \mathrm{ng} / \mu \mathrm{L})$ and $5 \mu \mathrm{L}$ of $20 \mathrm{mM}$ disuccinimidyl suberate (DSS) were introduced into the flow cell for $30 \mathrm{~min}$ and washed again with PBS buffer. During this time period, $1 \mu \mathrm{L}$ of $0.25 \%$ anti-digoxigenin coated bead (diameter $1 \mu \mathrm{m}), 2 \mu \mathrm{L}$ of digoxigenin-3500 bp DNA-anti-biotin $(25 \mathrm{ng} / \mu \mathrm{L})$ and $5 \mu \mathrm{L}$ of biotinylated pMHC ( $4 \mu \mathrm{g} / \mathrm{ml})$ were mixed and diluted to $35 \mu \mathrm{L} ; 20 \mu \mathrm{L}$ was added to the flow cell, and incubated for 30 min to form tethers. After washing with $30 \mu \mathrm{L}$ of PBS buffer, the flow cell was sealed with nail polish and loaded on the optical-trapping instrument for 
measurements. Tethers were found by eye, centered using an automated procedure (3), and trapped with typical stiffness of $\sim 0.20 \mathrm{pN} / \mathrm{nm}$. Bead positions were sampled at $3 \mathrm{kHz}$, antialiasfiltered at $1.5 \mathrm{kHz}$, and recorded until bond rupture. Control experiments where CAR antibody was excluded from the assay resulted in no tethers.

Generation of $\boldsymbol{\alpha} \boldsymbol{\beta}$ TCR and CAR T-cells. A total of 6.5 x 105 HEK293 cells per well were seeded onto 6 well plate one day before transfection and incubated at $37^{\circ} \mathrm{C}$. with $5 \% \mathrm{CO}_{2}$. The cells were then transfected with packaging plasmid and lentiviral vector using polyethylenimine (PEI), and the medium was replaced after $12 \mathrm{hrs}$. The viral supernatant was harvested twice in the following two days. The collected viral supernatant was titred, filtered by a 0.45 um membrane filter (Millipore) and concentrated by a $100 \mathrm{~K}$ ultracentrifuge tube (Millipore). For lentivirus transductions, polybrene and HEPES were added at 8-10 ug/ml and $10 \mathrm{mM}$, respectively, with Jurkat cells at $1 \times 10^{6}$ cells per well in $1 \mathrm{ml}$, followed by spinoculation at 2,500 rpm for $2 \mathrm{hrs}$. After $24 \mathrm{hrs}$, cells and viral solutions were separated, and cells were cultured in the maintenance medium. After an additional $48 \mathrm{hrs}$ culture period, flow cytometry analysis was performed to check the expression of the constructs. 


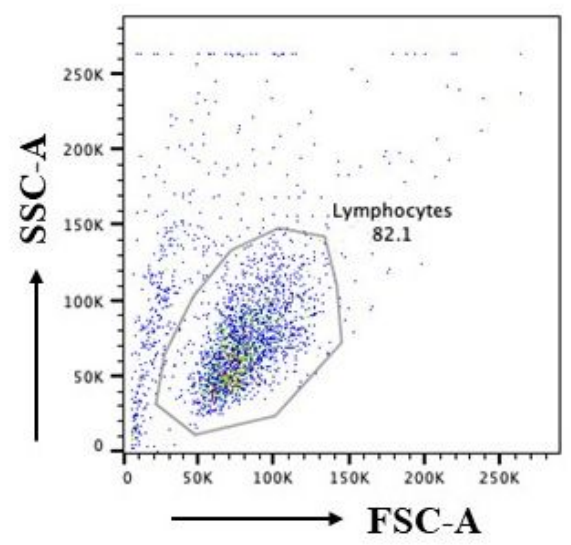

Un-transduced cell

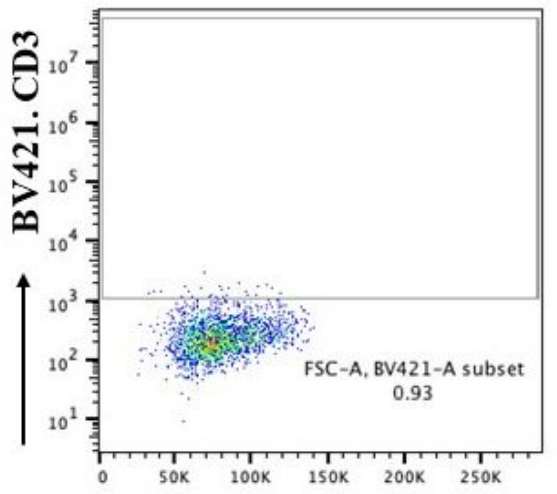

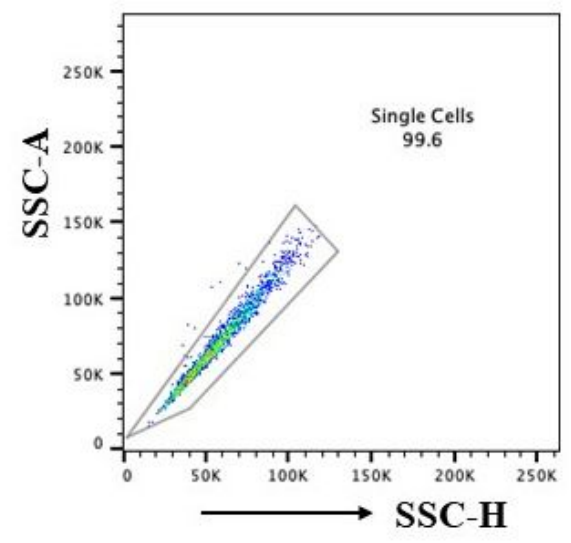

Transduced cell

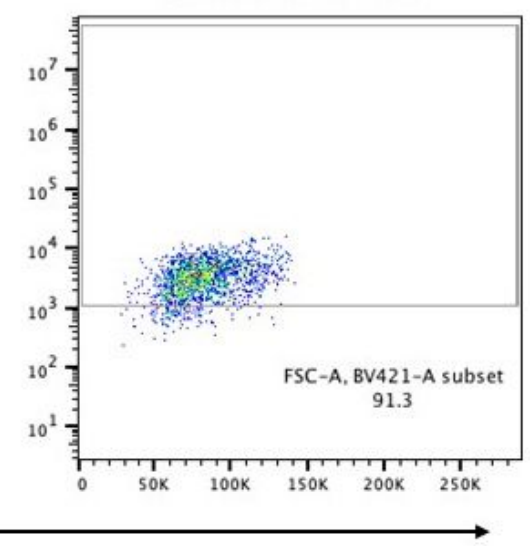

FSC-A

Figure S1. The expression of A*0201 restricted LMP2A specific TCR on transduced Jurkat 76 cells was measured using BV421 Mouse Anti-Human CD3 staining. This result shows that $91.3 \%$ of successful transduction and expression of the desired TCR on Jurkat 76 cells. 


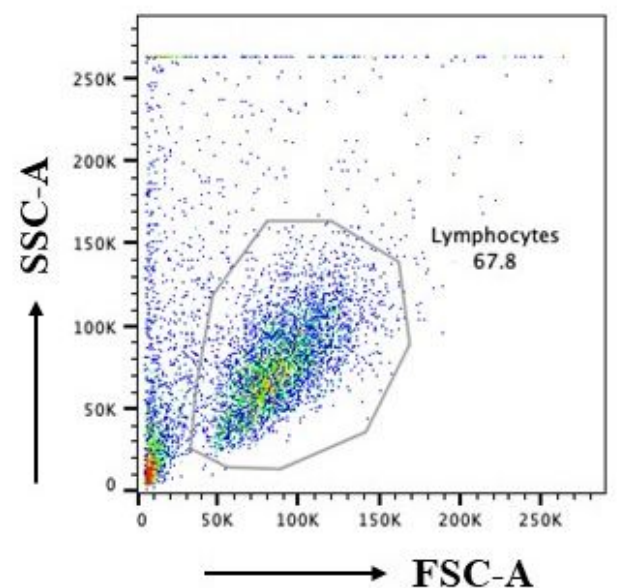

Un-transduced cell

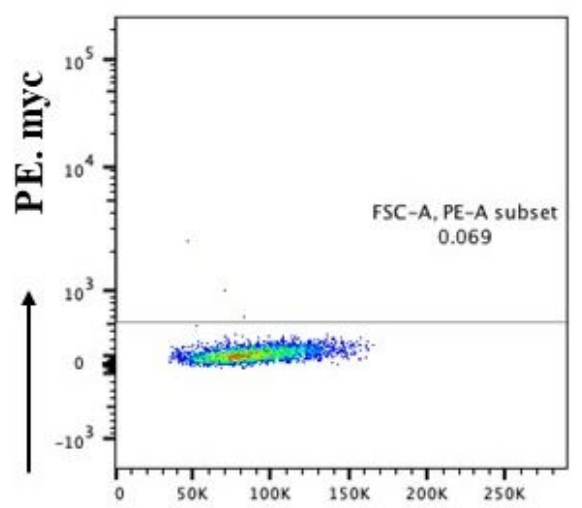

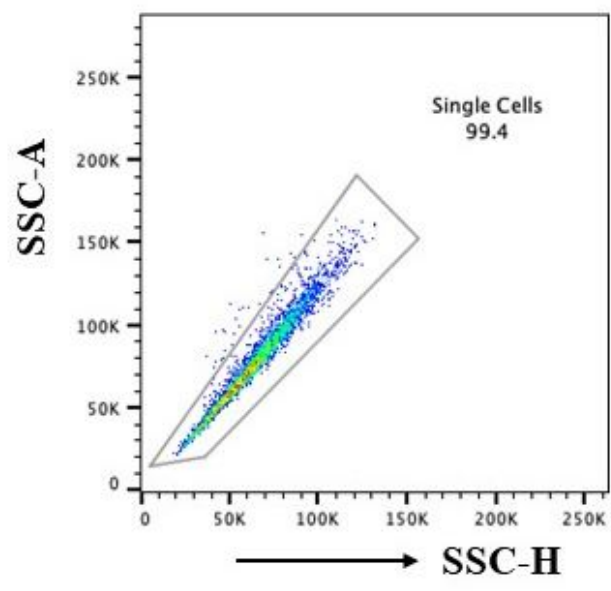

Transduced cell

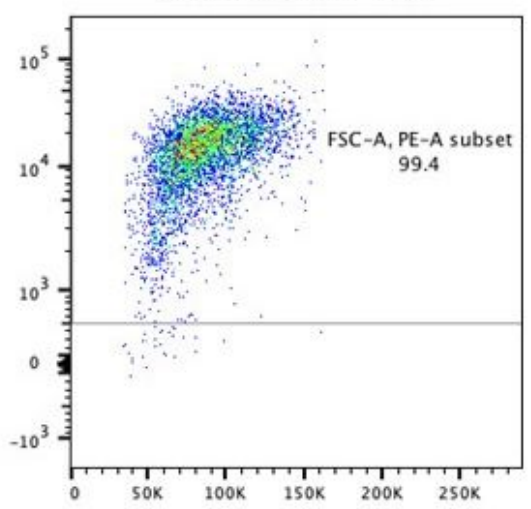

FSC-A

Figure S2. The expression of A*0201 restricted LMP2A specific CAR on transduced Jurkat 76 cells was measured using Anti-Myc taganti-Myc tag PE-conjugated antibody. This result shows that $99.4 \%$ of successful transduction and expression of the desired CAR on Jurkat 76 cells. 

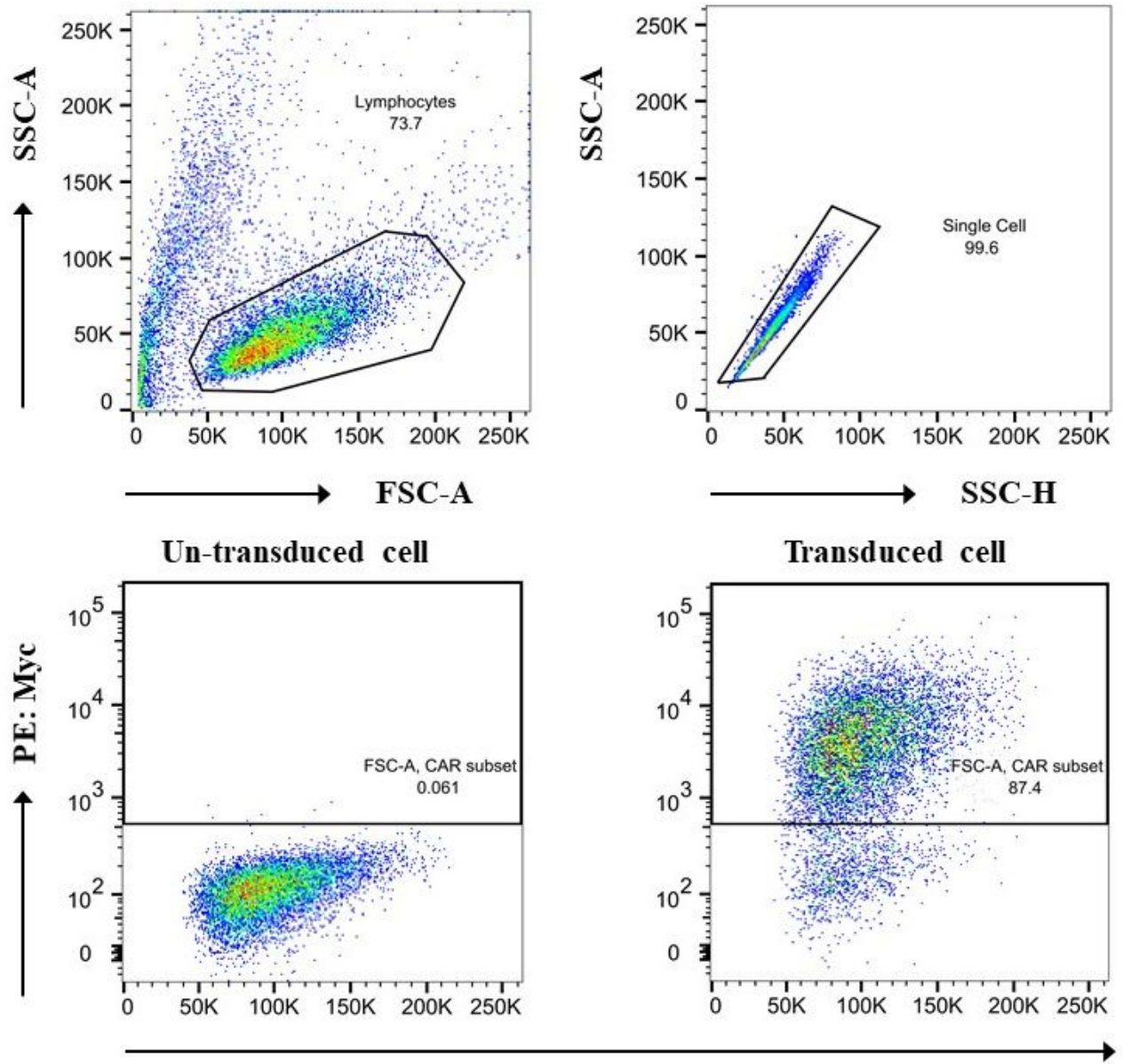

FSC-A

Figure S3. The expression of A*0201 restricted LMP1A specific CAR on transduced Jurkat 76 cells was measured using anti-Myc tag PE-conjugated antibody. This result shows that $87.4 \%$ of successful transduction and expression of the desired CAR on Jurkat 76 cells. 

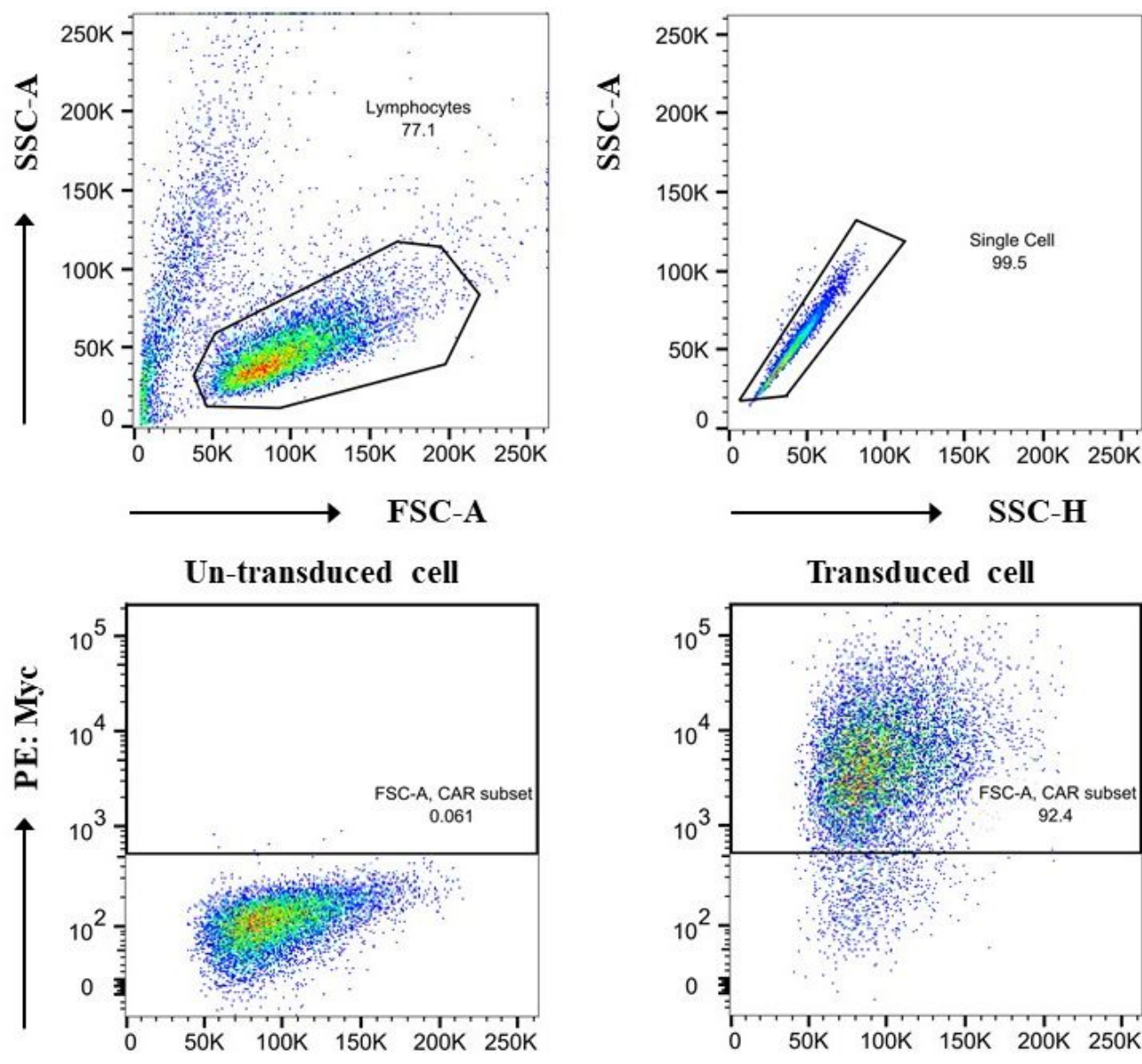

\section{Transduced cell}

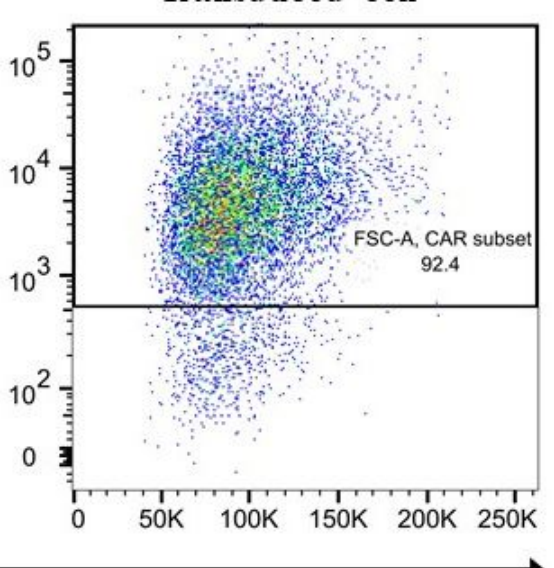

FSC-A

Figure S4. The expression of CD19 CAR on transduced Jurkat 76 cells was measured using anti-Myc tag PE-conjugated antibody. This result shows that $92.4 \%$ of successful transduction and expression of the desired CAR on Jurkat 76 cells. 


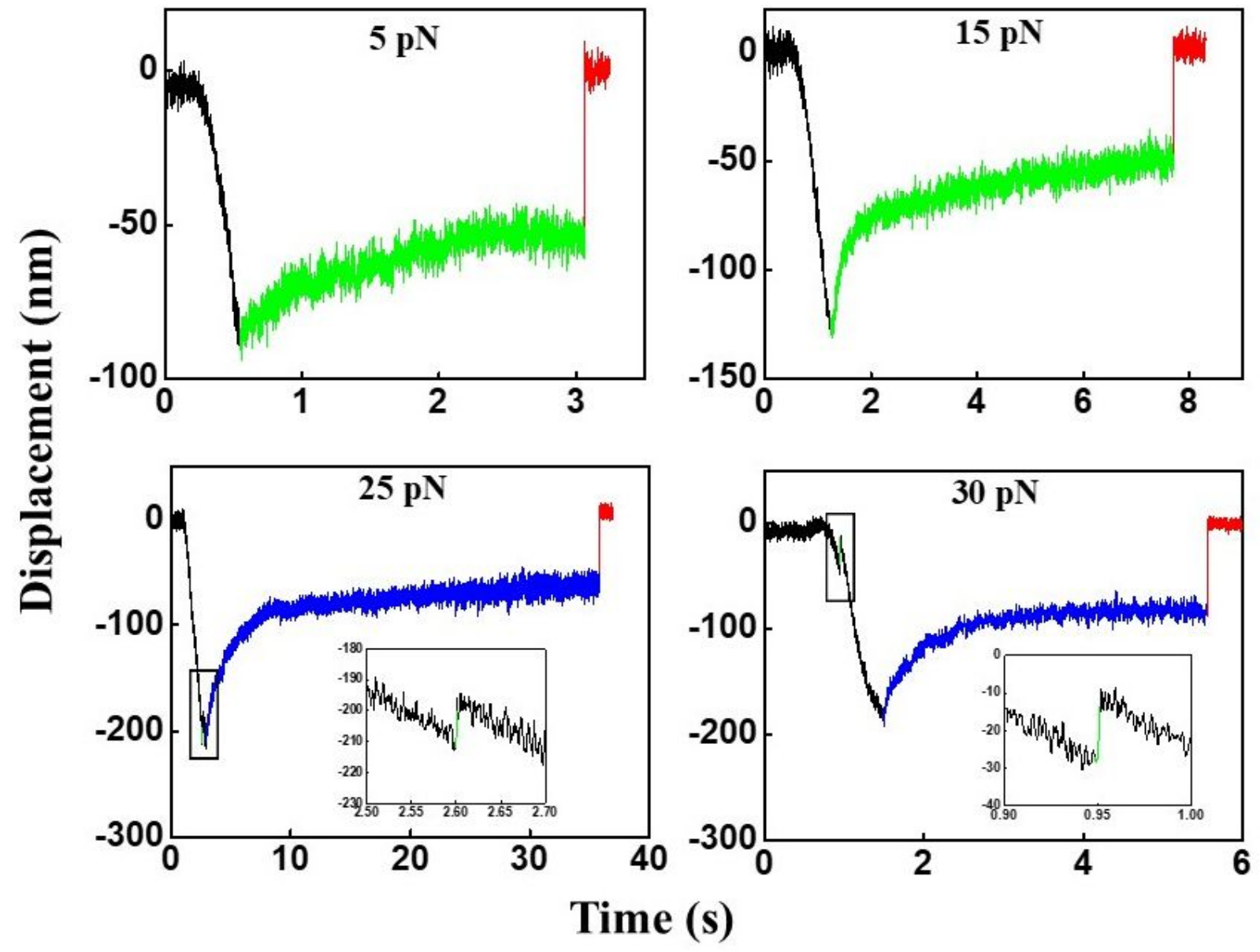

Figure S5. Representative SMSC traces $(5 \mathrm{pN}, 15 \mathrm{pN}, 25 \mathrm{pN}$ and $30 \mathrm{pN})$ of LMP1 CARLMP1/A*0201 interaction with conformational transition (see the black rectangles and expanded plots) found at higher forces. $12 \%$ of total traces contain such transition. 


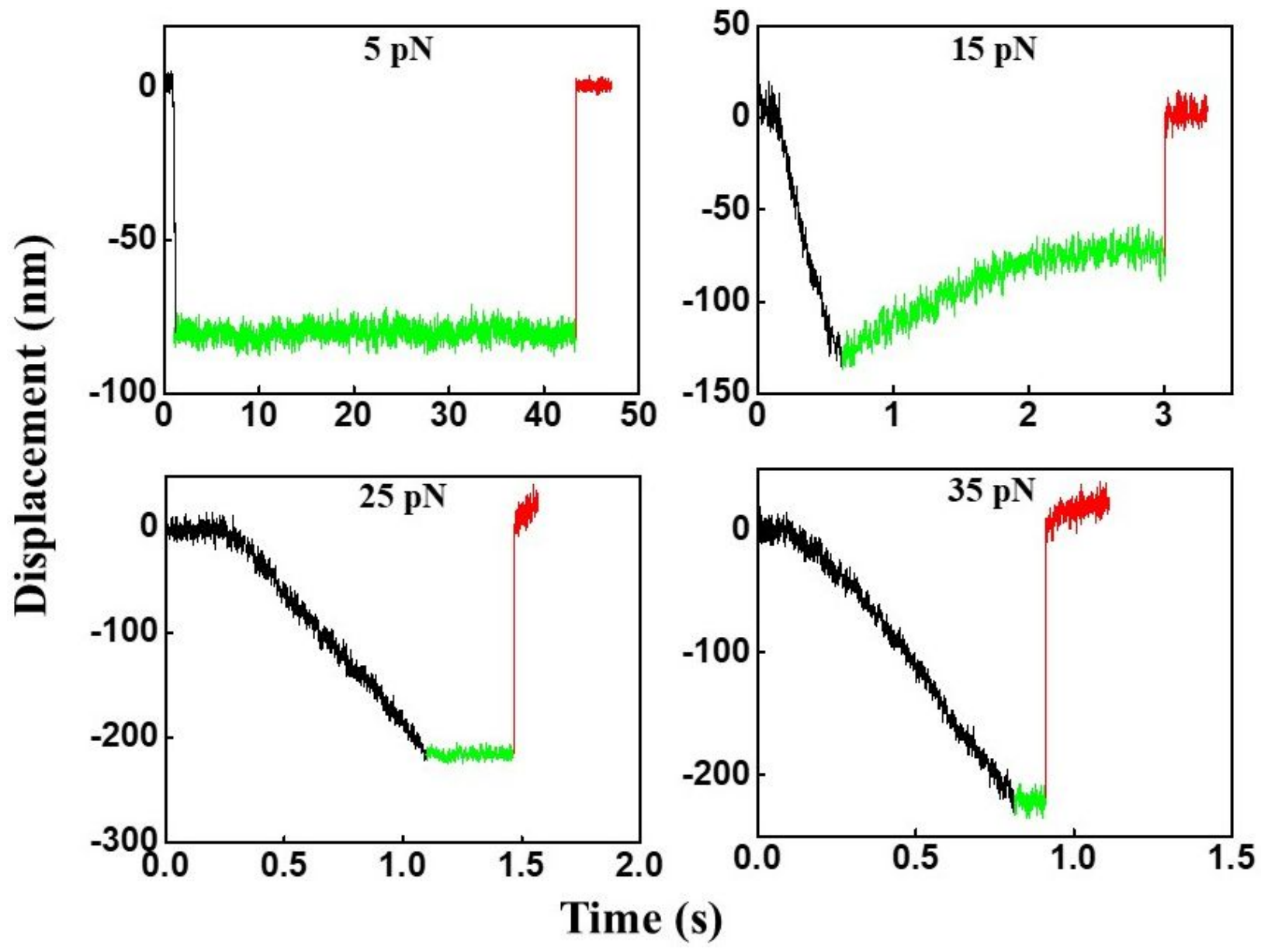

Figure S6. Representative SMSC traces ( 5 pN, 15 pN, 25 pN and 35 pN) of CD19 CAR-CD19 interaction with no conformational transition observed. 

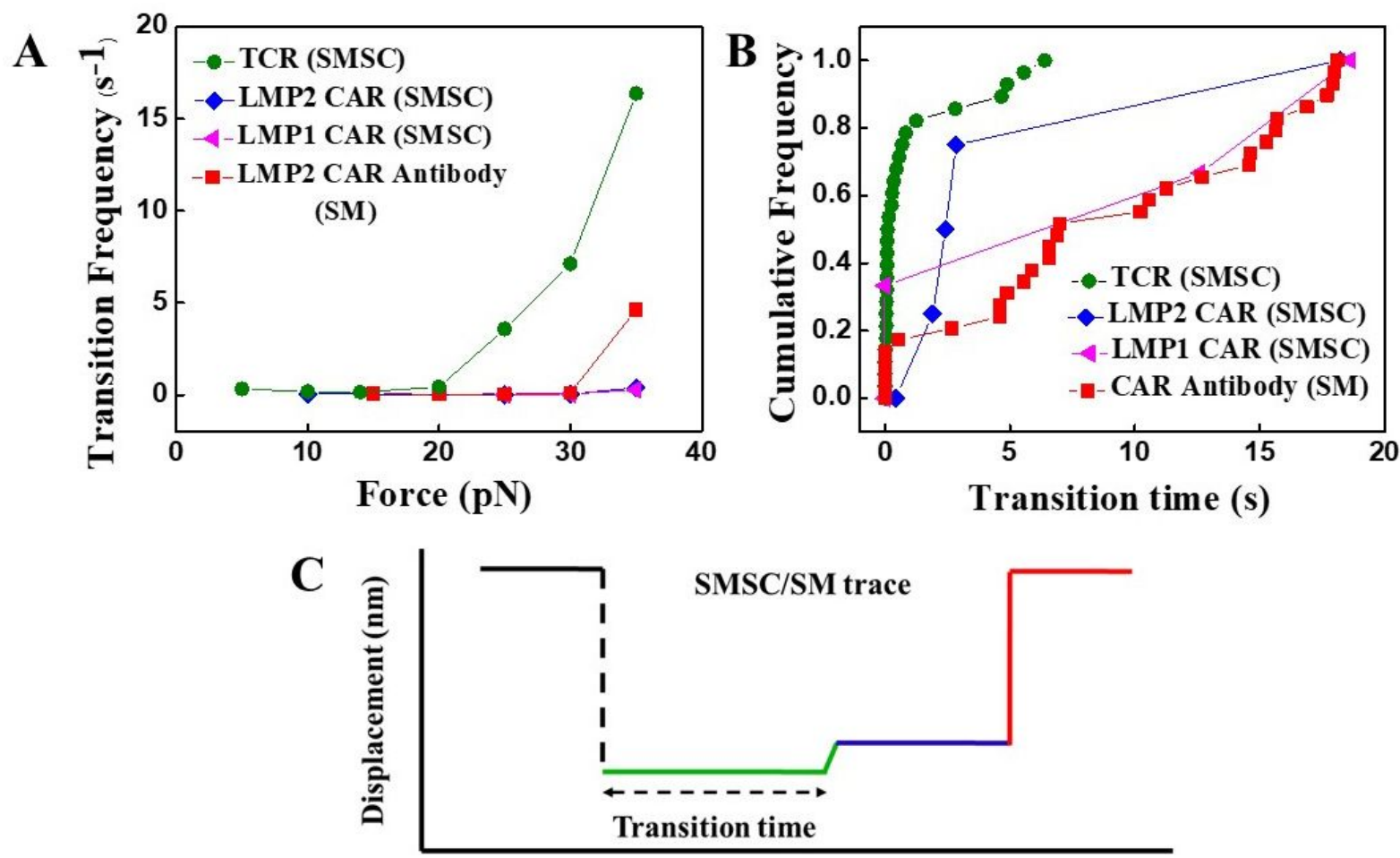

Time (s)

Figure S8. (A) Conformational transition frequency vs. force and (B) cumulative frequency vs. transition time plot for TCR (SMSC), LMP2 CAR (SMSC), LMP1 CAR (SMSC) and LMP2 CAR antibody (SM) interacting with agonist peptides. (C) Representative SMSC/SM trace showing the transition time defined in this analysis as the time between the end of the ramp when the force reaches a maximum and the appearance of the transition (green to blue). For example, the transition time of LMP2 CAR (SMSC) system is $18.2 \mathrm{~s}$ (see Fig. 3) at $25 \mathrm{pN}$. The transition frequency at a given force is determined by dividing the number of observed transitions ( 2 in the case of $25 \mathrm{pN}$ for the LMP2 CAR) by the sum of the transition times (green segment in $\mathrm{C}$ and bold below) for traces that transition plus the total time that the system is under load for traces that don't transition. In this case it would contain contributions from 7 traces. Therefore, the transition frequency is calculated as $2 /(\mathbf{1 8 . 2}+\mathbf{2 . 4}+26.0+30.2+29.9+24.8+25.9)=0.013 \mathrm{~s}^{-1}$. 


\begin{tabular}{|l|c|c|c|c|c|c|}
\hline & \multicolumn{5}{|c|}{ Force ranges (pN) } \\
\cline { 2 - 7 } & $5-9$ & $10-15$ & $16-20$ & $21-25$ & $26-30$ & $31-35$ \\
\hline $\begin{array}{l}\text { No. of SMSC traces with TCR } \\
(\mathrm{n}=37)\end{array}$ & 8 & 8 & 5 & 5 & 6 & 5 \\
\hline $\begin{array}{l}\text { No. of SMSC traces with LMP2 CAR } \\
(\mathrm{n}=31)\end{array}$ & 5 & 5 & 4 & 7 & 5 & 5 \\
\hline $\begin{array}{l}\text { No. of SMSC traces with LMP1 CAR } \\
(\mathrm{n}=34)\end{array}$ & 5 & 7 & 5 & 7 & 5 & 5 \\
\hline $\begin{array}{l}\text { No. of SMSC traces with CD19 CAR } \\
(\mathrm{n}=33)\end{array}$ & 8 & 5 & 5 & 6 & 5 & 4 \\
\hline $\begin{array}{l}\text { No. of SM traces with CAR Antibody } \\
(\mathrm{n}=56)\end{array}$ & 9 & 7 & 9 & 12 & 10 & 9 \\
\hline $\begin{array}{l}\text { No. of SM traces with BB7.2 } \\
\text { Antibody (n=46) }\end{array}$ & 10 & 8 & 7 & 8 & 7 & 6 \\
\hline
\end{tabular}

Table S1: Number of SMSC and SM traces obtained at different force ranges.

\begin{tabular}{|l|c|c|c|c|c|c|}
\hline & \multicolumn{5}{|c|}{ Force ranges (pN) } \\
\cline { 2 - 7 } & $5-9$ & $10-15$ & $16-20$ & $21-25$ & $26-30$ & $31-35$ \\
\hline $\begin{array}{l}\text { No. of SMSC transitions with TCR (n } \\
=29)\end{array}$ & 3 & 6 & 4 & 5 & 6 & 5 \\
\hline $\begin{array}{l}\text { No. of SMSC transitions with LMP2 } \\
\text { CAR (n = 5) }\end{array}$ & 0 & 1 & 0 & 2 & 1 & 1 \\
\hline $\begin{array}{l}\text { No. of SMSC transitions with LMP1 } \\
\text { CAR (n = 4) }\end{array}$ & 0 & 0 & 0 & 2 & 1 & 1 \\
\hline $\begin{array}{l}\text { No. of SM transitions with LMP2 } \\
\text { CAR Antibody (n=30) }\end{array}$ & 0 & 2 & 2 & 11 & 8 & 7 \\
\hline $\begin{array}{l}\text { No. of SM transitions with BB7.2 } \\
\text { Antibody (n=10) }\end{array}$ & 0 & 0 & 0 & 0 & 5 & 5 \\
\hline
\end{tabular}

Table S2: Number of SMSC and SM transitions identified at different force ranges. 


\section{References:}

(1) Kim, S. T.; Takeuchi, K.; Sun, Z. -Y. J.; Touma, M.; Castro, C. E.; Fahmy, A.; Lang, M. J.; Wagner, G.; Reinherz, E. L. The $\alpha \beta$ T Cell Receptor is an Anisotropic Mechanosensor. $J$. Biol. Chem. 2009, 284, 31028-31037.

(2) Shin, Y.; Davis, J. H.; Brau, R. R.; Martin, A.; Kenniston, J. A.; Baker, T. A.; Sauer, R. T.; Lang, M. J. Single-Molecule Denaturation and Degradation of Proteins by the AAA + ClpXP Protease. Proc. Natl. Acad. Sci. U.S.A. 2009, 106, 19340-19345.

(3) Lang, M. J.; Asbury, C. L.; Shaevitz J. W.; Block S. M. An Automated Two-Dimensional Optical Force Clamp for Single Molecule Studies. Biophysical Journal 2002, 83, 491-501. 